\title{
Seminal somatostatin in men with spinal cord injury
}

\author{
L Ødum ${ }^{1}, \mathrm{~J}$ Sønksen ${ }^{2}$ and F Biering-Sørensen ${ }^{3}$ \\ ${ }^{1}$ Department of Clinical Biochemistry, Bispebjerg Hospital, University of Copenhagen, Bispebjerg Bakke 23, \\ DK-2400 Bispebjerg and Department of Clinical Biochemistry, Rigshospitalet; ${ }^{2}$ Department of Urology; ${ }^{3}$ Centre \\ for Spinal Cord Injured, Rigshospitalet, National University Hospital, Blegdamsvej 9, DK-2100 Copenhagen, \\ Denmark
}

\begin{abstract}
Somatostatin is present in high concentrations in human seminal plasma. Semen was obtained from men with spinal cord injury by vibratory-and/or electrostimulation. The seminal somatostatin concentration and sperm motility rate depended on the location of the spinal cord lesion. In men with lesions at or above T6 the seminal plasma concentration was significantly decreased compared to healthy men and to patients with lesions below T6 $(P<0.005)$. The latter group did not differ from healthy men. Men with spinal cord lesions below T6 had significantly decreased sperm motility rates $(P=0.09)$ compared to patients with lesions at or above T6. Seminal somatostatin concentrations were similar in vibratory- and electrostimulated ejaculates. The seminal somatostatin concentration, semen volume, sperm count, motility and morphology in each patient was not affected when repeated vibratory ejaculations were performed at home.
\end{abstract}

Keywords: ejaculation; semen; somatostatin; spinal cord injuries

\section{Introduction}

Men with spinal cord injury (SCI) suffer in general from ejaculatory dysfunction. ${ }^{1}$ By penile vibratory stimulation or rectal electrostimulation it is possible to retrieve sperm from the vast majority of SCI men. ${ }^{1,2}$ However, the semen quality in SCI men is often poor. ${ }^{2,3}$ In particular, low motility and viability of spermatozoa obtained by electrostimulation have been noted and only a minority of SCI men have normal cervical mucus penetration tests. ${ }^{3}$ The reasons for these deficiencies are uncertain. Hirsh $\mathrm{et} \mathrm{al}^{4}$ demonstrated a low mean spermatid and high Sertoli cell count per seminiferous tubule in testis biopsies from SCI men. Neurogenic factors may play a role, as indicated by the fact that the most severe effects on maturation of the germinal cells are seen when the spinal cord lesion includes T10-L2. ${ }^{5}$

Human seminal plasma contains high concentrations of somatostatin, the concentrations being approximately 200 times higher than in blood plasma. ${ }^{6}$ The molecular form has been identified as somatostatin- $64,{ }^{6}$ in contrast to somatostatin-14 found in many tissues and somatostatin- 28 most prominent in the intestine. ${ }^{7}$ Somatostatin, acting as a hormone or a neurotransmitter, behaves as an inhibitor of cell functions including hormone secretion, muscle contraction and cell growth. ${ }^{8}$ As the concentration of somatostatin-64 in seminal plasma from vasectomised men is significantly higher than in normal men, the synthesis of somatostatin- 64 possibly takes place in the male accessory sex glands. ${ }^{6}$

The aim of the present study was to determine the seminal concentration of somatostatin and investigate if it could be correlated with semen quality (sperm count, volume, motility and morphology) in SCI men.

\section{Materials and methods}

Patients

Twelve SCI men were included in this study (Table 1) with a median age of 30 years (range 21-45 years). Median interval from SCI to study entry was 7 years (range 1-29 years). The level of spinal cord lesions was determined as the most caudal, normal functioning spinal cord segment. In complete lesions no sacral sparing was present. The neurological level of the cord lesion ranged from $\mathrm{C} 2$ to $\mathrm{T} 12$. Nine lesions were complete and three incomplete. None of the patients was able to obtain antegrade ejaculation during normal sexual stimulation. The study protocol was approved by the regional ethical committee, and patients were included only when oral and written informed consent was obtained.

\section{Semen retrieval}

All patients underwent penile vibratory stimulation to induce ejaculation as described by Sønksen et al, ${ }^{1}$ with a vibrator calibrated to a peak-to-peak amplitude of $2.5 \mathrm{~mm}$ and a frequency of $100 \mathrm{~Hz}$. Rectal electrostimulation ${ }^{9}$ was performed if no antegrade ejaculation was obtained by penile vibratory stimulation. However, two patients (patients 7 and 10, see Table 1) obtaining antegrade ejaculation by vibratory stimulation had also had electrostimulation resulting in antegrade ejaculation.

Five patients underwent a home programme of 
repeated vibratory stimulation to induce ejaculation once weekly for a period between 6 and 12 months. Antegrade ejaculates were obtained for semen and somatostatin analysis every 3 months in the outpatient clinic.

\section{Semen analysis}

Semen analyses of the antegrade ejaculates were carried out within $40 \mathrm{~min}$ of ejaculation. The volume, sperm count, motility and morphology were determined according to WHO laboratory standards. ${ }^{10}$

\section{Seminal plasma extraction}

Semen was frozen at $-20^{\circ} \mathrm{C}$ within $30 \mathrm{~min}$. Upon thawing proteinase inhibitors were added to the following final concentrations: benzamidine $50 \mathrm{mM}$, EDTA $0.3 \mathrm{mM}$, leupeptin $1 \mu \mathrm{M}$, pepstatin $0.5 \mu \mathrm{M}$ and PMSF $100 \mu \mathrm{M}$. The sperm was centrifuged at $2000 \mathrm{G}$ for $20 \mathrm{~min}$ at $4^{\circ} \mathrm{C}$ and seminal plasma was isolated. The extraction of the seminal plasma was performed by adding one volume to four volumes of boiling water and boiling for $45 \mathrm{~min}^{6}$

\section{Immunoassay}

Somatostatin was measured using antiserum R37 (kindly provided by Dr Jens F Rehfeld, Department of Clinical Biochemistry, Rigshospitalet, the National University Hospital, Copenhagen, Denmark) directed against the sequences -Cys-Lys-Asn-Phe-Phe- in somatostatin-14 produced in rabbits as previously described. ${ }^{11}$ Tracer, incubation condition and separation were in accordance with the previous description by $\emptyset$ dum et al. ${ }^{12}$ Detection limit of the assay is $0.1 \mathrm{nmoll}^{-1}$.

\section{Statistical analysis}

The Mann-Whitney two-sample rank sum test was used.

\section{Results}

Patient data are shown in Table 1. In addition seminal plasma somatostatin concentrations and sperm motility rates are shown. No difference between the concentrations of somatostatin in the vibrated (median $=0$ nmol $1^{-1}$, range: $0-13.8, n=7$ ) and electrostimulated patients $\left(\right.$ median $=2.8 \mathrm{nmoll}^{-1}$, range: $\left.0-5.6, n=7\right)$ was detected $(P=0.62)$. As seen from Table 1 , semen from patients with spinal cord lesions at T6 or above contained no somatostatin in the first sample obtained. The somatostatin concentration in this group was significantly lower $(P<0.005)$ than that of healthy men (median $=3.1 \mathrm{nmoll}^{-1}$, range: $\left.0.6-76\right)^{6}$ and significantly lower $(P<0.005)$ than in patients with spinal cord lesions below T6 (median $=4.3 \mathrm{nmol}^{-1}$, range: 0.5-13.8, first sample of each patient). In contrast, patients with spinal cord lesions below T6 had normal seminal plasma somatostatin concentrations.

The somatostatin concentration was not significantly affected by repeated vibration stimulated ejaculations performed at home, as indicated by rather constant concentrations at outpatient visits at 3 month intervals (Figure 1). Furthermore, no effects on the semen volume, sperm count, motility and morphology were seen by repeated vibration stimulated ejaculations.

Seminal plasma somatostatin concentration did not correlate with semen volume, sperm count, or morphology. Sperm motility rates in patients with spinal cord lesions below T6 (median $=0 \%$ motile, range: $0-30$ ) was marginally significantly $(P=0.09)$ lower than in patients with spinal cord lesions at or above T6 (median $=16 \%$ motile, range: $10-37)$.

There was a trend toward lower motility in samples containing somatostatin compared to samples without somatostatin (correlation coefficient $=-0.66$ ) (Table 1).

\section{Discussion}

Poor semen quality in SCI men has been attributed to several factors such as abnormal testicular histology,

Table 1 Patient and stimulation data, seminal somatostatin concentrations and sperm motility rates

\begin{tabular}{|c|c|c|c|c|c|c|}
\hline \multirow{2}{*}{$\begin{array}{l}\text { Patient } \\
1\end{array}$} & \multicolumn{2}{|c|}{ Spinal cord lesion } & \multirow{2}{*}{$\frac{\begin{array}{c}\text { Duration of } S C I \\
\text { (years) }\end{array}}{5}$} & \multirow{2}{*}{$\begin{array}{c}\begin{array}{c}\text { Type of stimulation } \\
\text { for ejaculation }\end{array} \\
\text { VIB }\end{array}$} & \multirow{2}{*}{$\frac{\begin{array}{c}\text { Somatostatin } \\
\left(\text { nmoll }^{-1}\right)(1 \text { st sample })\end{array}}{0}$} & \multirow{2}{*}{$\begin{array}{r}\begin{array}{r}\text { Motility (\%) } \\
\text { (1st sample) }\end{array} \\
37\end{array}$} \\
\hline & $\mathrm{C} 2$ & Com & & & & \\
\hline 2 & C5 & Com & 6 & VIB & 0 & 21 \\
\hline 3 & C6 & Inc & 7 & ES & 0 & 10 \\
\hline 4 & C6-7 & Com & 11 & VIB & 0 & 16 \\
\hline 5 & T5-6 & Com & 29 & ES & 0 & 10 \\
\hline 6 & T6 & Com & 1 & VIB & 0 & 16 \\
\hline 7 & $\mathrm{~T} 7$ & Inc & 2 & VIB & 13.8 & 0 \\
\hline 8 & $\mathrm{~T} 7$ & Com & 27 & VIB & 0.5 & 30 \\
\hline 9 & T7-8 & Com & 17 & ES & 5.1 & 0 \\
\hline 10 & T8 & Com & 7 & VIB & 5.8 & 0 \\
\hline 11 & Т9-10 & Inc & 8 & ES & 3.5 & 13 \\
\hline 12 & T11-12 & Com & 8 & ES & 2.0 & 0 \\
\hline
\end{tabular}

Com $=$ complete Inc $=$ incomplete $; \mathrm{VIB}=$ vibratory ES = electrostimulation

Patients 7 and 10 were also electrostimulated 


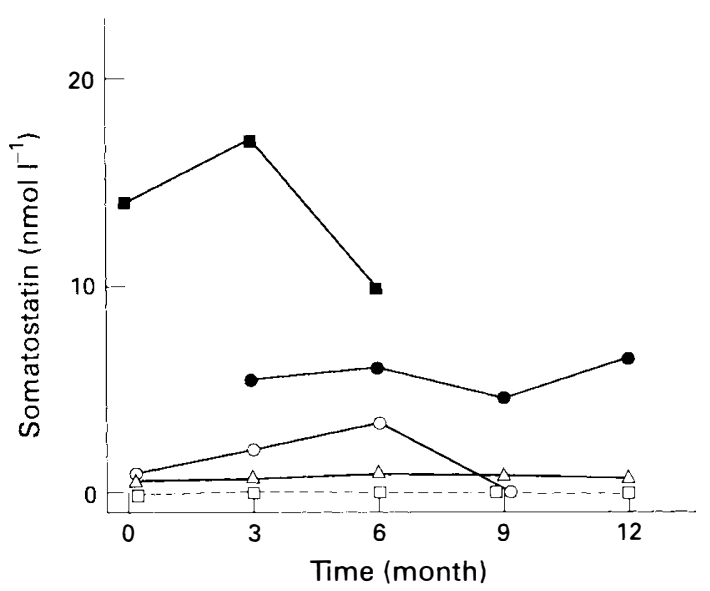

Figure 1 Seminal plasma somatostatin concentrations in repeated ejaculates. Semen was obtained by vibratory stimulation at 3 month intervals for periods up to 12 months. In the intervals, the patients performed vibratory stimulations at home once weekly. Patient 2: $\square--\square$, patient 4: $\triangle-\triangle$, patient 7: $\square-\square$, patient $8: \bigcirc-\bigcirc$, and patient 10 :

recurrent urinary tract infections, stasis of prostatic fluids and changes in the hypothalamic-pituitary axis. ${ }^{13}$ We found normal FSH, LH and testosterone levels in the patient group (not shown). Low sperm motility rates are well-known in SCI men. ${ }^{2,3,13}$ We observed this phenomenon in all patients when compared to WHO standards ${ }^{10}$ and, in particular, in the group of SCI men with lesions of low thoracolumbar spinal cord segments in accordance with histological changes of the testes in such patients. ${ }^{5}$

Somatostatin-64 does not originate from testis or epididymis, but possibly from male accessory sex glands. ${ }^{6}$ These glands are known to be innervated from sympathetic nerve fibres from the thoracolumbar spinal cord (T11-L2) and marginally from parasympathetic fibres from the sacral spinal cord (S2-S4).,14 Surprisingly, all patients with spinal cord lesions at or above T6 had no somatostatin in the seminal plasma. This might suggest that the secretion of somatostatin into the semen is dependent on nerve fibres arising above this level.

Seminal somatostatin did not correlate with semen volume, sperm count, or morphology. Motility was better in samples without than in samples with somatostatin although all samples were below WHO standards for sperm motility. ${ }^{10}$ Preliminary data suggest that somatostatin is not an inhibitor of sperm motility (unpublished data). Therefore, the negative correlation between seminal somatostatin and sperm motility may be a consequence of the SCI level rather than an effect of somatostatin on the motility. Apparently, the spinal cord level of T6 may be an important dividing line when consequences of the influence of SCI on semen quality are studied.

\section{Acknowledgements}

Lis Sørensen is thanked for skilful technical assistance. Also thanks to Department of Growth and Reproduction, Rigshospitalet, the National University Hospital, Copenhagen, Denmark, for semen analysis. The study was supported by grants from Gerda and Aage Haensch's Fond and the Danish Biotechnology Center for Neuropeptide Research.

\section{References}

1 Sønksen J, Biering-Sørensen F, Kristensen JK. Ejaculation induced by penile vibratory stimulation in men with spinal cord injuries. The importance of the vibratory amplitude. Paraplegia 1994; 32: 651-660.

2 Denil J et al. Functional characteristics of sperm obtained by electroejaculation. J Urol 1992; 39: 69-72.

3 Sønksen J, Biering-Sørensen F. Fertility in men with spinal cord or cauda equina lesions. Semin Neurol 1992; 12: 106-114.

4 Hirsch IH et al. Quantitative testicular biopsy in spinal cord injured men: comparison to fertile controls. J Urol 1991; 146: 337-341.

5 Chapelle PA et al. Trophic effects on testis in paraplegics. Paraplegia 1993; 31: 576-583.

6 Ødum L, Johnsen AH. Human seminal plasma contains somatostatin-64. Biochem J 1994; 303: 263-268.

7 Francis BH, Baskin DG, Saunders DR, Ensinck JW. Distribution of somatostatin-14 and somatostatin-28 in gastroentestinalpancreatic cells of rat and human. Gastroenterology 1990; 99: 1283-1291.

8 Lewin MJM. The somatostatin receptor in the GI tract. Annu Rev Physiol 1992; 54: 455-468.

9 Halstead LS, VerVoort S, Seager SWJ. Rectal probe electrostimulation in the treatment of anejaculatory spinal cord injured men. Paraplegia 1987; 25: 120-129.

10 World Health Organization. WHO Laboratory Manual for the Examination of Human Semen and Semen-cervical Mucus Interaction. Cambridge: Cambridge University Press, 1987.

11 Rehfeld JF. Sequence-specific radioimmunoassays for cholecystokinin, gastrin and somatostatin Biomed Res 1980; Suppl 1: 73-78.

12 Ødum L, Pildal J, Rehfeld JF. Somatostatin in the boar reproductive system. Eur J Endocrinol 1994; 130: 515-521.

13 Linsenmeyer TA, Perkash I. Infertility in men with spinal cord injury. Arch Phys Med Rehabil 1991; 72: 747-754.

14 Lechtenberg R, Ohl DA. Normal sexual function. In: Lectenberg R, Ohl DA (eds). Sexual Dysfunction. Lea and Febiger: Philadelphia, 1994, pp 21-43. 